\title{
Silver Nanoparticle Enhanced Chemiluminescence Method for the Determination of Nitrazepam
}

\author{
Suqin HAN, ${ }^{\dagger}$ Xia LI, and Bei WeI \\ School of Chemistry and Material Science, Shanxi Normal University, Linfen 041004, Shanxi, P. R. China
}

\begin{abstract}
We report on a simple and sensitive chemiluminescence (CL) method to determine nitrazepam. This method is based on the fact that rhodamine 6G (Rh6G) enhanced the weak CL emission of the reaction of hexacyanoferrate with nitrazepam, and that it was further enhanced by silver nanoparticles (AgNPs). The effects of the concentrations of $\mathrm{K}_{3} \mathrm{Fe}(\mathrm{CN})_{6}, \mathrm{Rh} 6 \mathrm{G}$, $\mathrm{AgNPs}$ and $\mathrm{NaOH}$ on the $\mathrm{CL}$ reaction were investigated. Under the optimum conditions, the CL intensity was proportional to the concentration of nitrazepam in the range from $1.0 \mathrm{nM}$ to $10.0 \mu \mathrm{M}$. The detection limit $(3 \sigma)$ was at $0.1 \mathrm{nM}$. The relative standard deviation was $2.1 \%$ (at a $0.1 \mu \mathrm{M}$ concentration and for $n=11$ ). The method was successfully applied to the determination of nitrazepam in Coca-Cola beverage, urine and plasma, and the recovery was $98-103 \%$. We also considered the possible CL reaction mechanism.
\end{abstract}

Keywords Silver nanoparticles, chemiluminescence, nitrazepam, rhodamine 6G, hexacyanoferrate

(Received January 12, 2014; Accepted January 22, 2014; Published April 10, 2014)

\section{Introduction}

Nitrazepam is widely used as an antiepileptic drug, and in some cases can be useful as an adjunct treatment in refractory epilepsy, and also as an anti-depressive and sedative drug. ${ }^{1}$ In recent years, it has become a drug of abuse, and has been implicated in cases of drug-facilitated assault, with the general modus operandi in these cases being through spiking the victim's drink. Therefore, various methods have been developed for the determination of nitrazepam, such as spectrophotometry, ${ }^{2,3}$ fluorescence spectrometry, ${ }^{4}$ voltammetry, ${ }^{5,6}$ liquid chromatography ${ }^{7,8}$ and capillary electrophoresis. ${ }^{9,10}$ However, these methods either suffer from low sensitivity, narrow linear range, and the use of volatile organic solvents, or are timeconsuming and expensive to implement.

Chemiluminescence (CL) has taken a strong position among the more mundane analytical techniques used during the last several decades because of a triumvirate of inherent strengths: sensitivity, simplicity, and, in many cases, a wide linear detection range. Recently, nanoparticles (NPs) have been applied in CL reactions, ${ }^{11-14}$ which have provided new approaches to enhance the inherent sensitivity and to expanded new applications in detections. Among these NPs, silver NPs (AgNPs) have attracted particular attention because of their excellent catalytic and electrocatalytic activities. ${ }^{15}$ It has been reported that the AgNPs as catalysts are mainly used for the luminol CL system, ${ }^{15-17} \mathrm{Ce}(\mathrm{IV}) \mathrm{CL}$ system ${ }^{18}$ and peroxalate CL system. ${ }^{19}$ To the best of our knowledge, the catalytic effect of AgNPs on the $\mathrm{CL}$ of the $\mathrm{K}_{3} \mathrm{Fe}(\mathrm{CN})_{6}$ system has not been investigated; further no CL method was reported for the determination of nitrazepam.

$\dagger$ To whom correspondence should be addressed.

E-mail: hsq@dns.sxnu.edu.cn
In this paper, we proposed the CL method for the determination of nitrazepam, based on the fact that rhodamine $6 \mathrm{G}(\mathrm{Rh} 6 \mathrm{G})$ could enhance the weak CL emission of the reaction of $\mathrm{K}_{3} \mathrm{Fe}(\mathrm{CN})_{6}$ with nitrazepam, which was further enhanced by AgNPs. The enhanced CL intensity was proportional to the nitrazepam concentration over a wide range. Based on these phenomena, a simple, rapid and sensitive flow-injection CL method has been developed for the determination of nitrazepam. The proposed method was successfully applied to the determination of nitrazepam in beverage and human fluid samples with satisfactory results.

\section{Experimental}

Reagents and materials

All chemicals and reagents were of analytical grade and used without further purification; deionized and ultrapure water was used throughout. Nitrazepam was purchased from National Institute for the Control of Pharmaceutical and Biological Products (Beijing, China). A $0.01 \mathrm{M}$ nitrazepam stock solution was prepared by dissolving nitrazepam in a $0.1 \mathrm{M}$ sodium hydroxide solution and diluting with water. Work solutions were prepared from the stock solution by appropriate dilution with water before use. A $0.01 \mathrm{M}$ stock solution of $\mathrm{K}_{3} \mathrm{Fe}(\mathrm{CN})_{6}$ (Shanghai Chemical Reagent Plant, China) was prepared with water, and work solutions of $\mathrm{K}_{3} \mathrm{Fe}(\mathrm{CN})_{6}$ were prepared as needed with a $1.0 \mathrm{M} \mathrm{NaOH}$ solution, which was chosen as the $\mathrm{CL}$ reaction medium. The stock solution of $1.0 \mathrm{mM}$ Rh6G (Shanghai Chemical Reagent Plant) was prepared with ultrapure water. $\mathrm{AgNO}_{3}, \mathrm{NaBH}_{4}$, and polyvinylpyrrolidone (PVP, the mean molecular weight is about $10000 \mathrm{~g} / \mathrm{moL}$ ) were obtained from Sinopharm Group Chemical Reagent Co., Ltd. (Shanghai, China). 


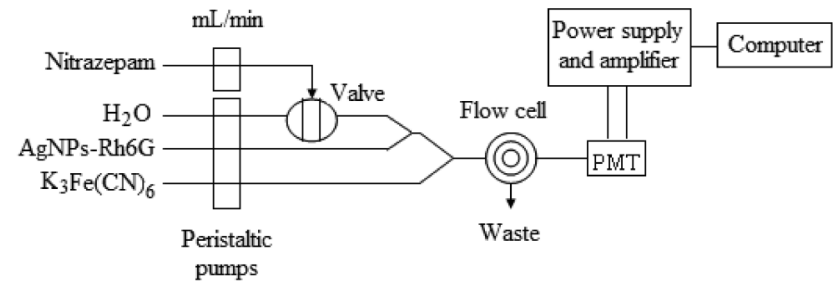

Fig. 1 Schematic diagram of the flow-injection CL for the determination of nitrazepam.

\section{Apparatus}

The CL measurements were conducted on a Model IFFL-D flow-injection CL analyzer (Xi' an Remex Analysis Instrument Co., Ltd., Xi' an, China). The CL spectra were performed on a Model Cary Eclipse fluorescence spectrophotometer (Varian, USA), and the UV-visible absorption spectra were performed on a Model WFZ-26A spectrophotometer (Tianjin, China), respectively. AgNPs were characterized with a JEM-2100 transmission electron microscope (TEM, JEOL, Japan).

\section{Synthesis of AgNPs}

AgNPs were prepared according to the literature ${ }^{20}$ with some

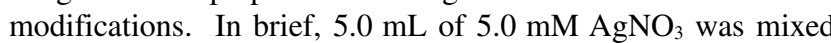
with a $20.0 \mathrm{~mL} \mathrm{3 \%} \mathrm{PVP} \mathrm{aqueous} \mathrm{solution} \mathrm{with} \mathrm{stirring} \mathrm{for} 2 \mathrm{~h}$. Then, $25 \mathrm{~mL}$ of $5.0 \mathrm{mM} \mathrm{NaBH}_{4}$ was added dropwise into the mixture while vigorously stirring simultaneously. The color of the mixture visibly and gradually changed to yellow. The reaction was conducted at room temperature for $30 \mathrm{~min}$ and aged for 2 days at $4^{\circ} \mathrm{C}$. A statistical analysis of TEM data revealed that the average diameter of the AgNPs was about $14 \pm 2 \mathrm{~nm}$. The absorption spectrum of AgNPs showed a peak at $395 \mathrm{~nm}$. Based on the concentration of the $\mathrm{AgNO}_{3}$ solution used in the preparation, the concentration of the as-prepared AgNPs was $0.5 \mathrm{mM}$.

\section{Procedures of CL assay}

A schematic diagram of the flow-injection CL system is shown in Fig. 1. Two peristaltic pumps were used to deliver flow streams. PTFE tubing was used to connect all components of the flow system. A flow cell (spiral glass tubing) was positioned in front of the detection window of the photomultiplier tube (PMT). Ultrapure water was used as a carrier to carry the standard or sample solutions of nitrazepam, which was merged with the mixed solution of AgNPs and Rh6G. Mixed solutions of nitrazepam, AgNPs and Rh6G reacted with $\mathrm{K}_{3} \mathrm{Fe}(\mathrm{CN})_{6}$, and were then put into the flow cell. The CL signal was monitored by the PMT, and imported to the computer for data acquisition.

\section{Results and Discussion}

\section{Kinetic curve of the $C L$ reaction}

The intensity profiles of the $\mathrm{K}_{3} \mathrm{Fe}(\mathrm{CN})_{6}$-nitrazepam-Rh6G CL reaction catalyzed by AgNPs are shown in Fig. 2. From these curves, it could be seen that the reaction of $\mathrm{K}_{3} \mathrm{Fe}(\mathrm{CN})_{6^{-}}$ nitrazepam produced a weak CL signal in the alkaline medium, and that adding Rh6G had a slight strengthening effect. When AgNPs was introduced into the $\mathrm{K}_{3} \mathrm{Fe}(\mathrm{CN})_{6}$-nitrazepam-Rh6G system, the CL signal were dramatically reinforced. The kinetic curve indicated that the CL system was rapid and sensitive enough. To exclude the effect of unreacted species in AgNP dispersion, the colloid was precipitated by a $0.1 \mathrm{M} \mathrm{KNO}_{3}$

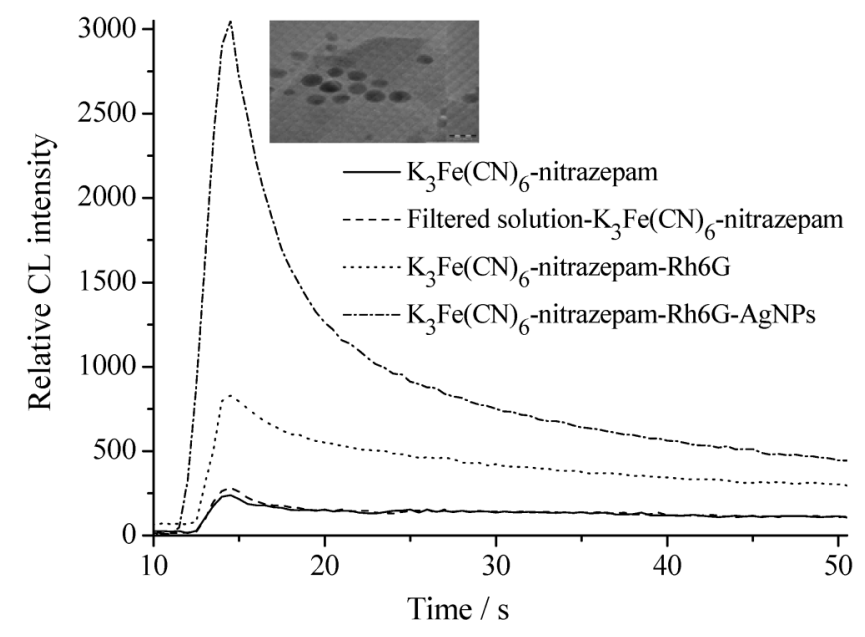

Fig. 2 CL kinetic curve. Conditions: $40.0 \mu \mathrm{M} \mathrm{K} \mathrm{K}_{3} \mathrm{Fe}(\mathrm{CN})_{6} ; 1.0 \mathrm{M}$ $\mathrm{NaOH} ; 8.0 \mu \mathrm{M}$ Rh6G; $8.0 \mu \mathrm{M}$ AgNPs; $1.0 \mu \mathrm{M}$ nitrazepam. The inset shows a TEM image of AgNPs.

solution, ${ }^{14,16}$ and filtered in order to remove the resultant precipitates. Negligible CL enhancement was obtained with the addition of the filtered solution, indicating a sensitized effect imposed by AgNPs on the CL system, instead of the concomitants in the colloid AgNPs. Therefore, a new CL method was established to perform the determination of nitrazepam.

\section{Optimization of the reaction conditions}

To obtain the highest sensitivity, the CL reaction conditions, the flow rate and a negative high voltage were optimized. A $0.1 \mu \mathrm{M}$ nitrazepam standard solution was used for optimization experiments (Fig. 3).

The influence of the $\mathrm{K}_{3} \mathrm{Fe}(\mathrm{CN})_{6}$ concentration was determined. It was shown that the maximum intensity was obtained at a $\mathrm{K}_{3} \mathrm{Fe}(\mathrm{CN})_{6}$ concentration of $40.0 \mu \mathrm{M}$. When the $\mathrm{K}_{3} \mathrm{Fe}(\mathrm{CN})_{6}$ concentration was above this level, the CL intensity decreased. Thus, $40.0 \mu \mathrm{M} \mathrm{K}_{3} \mathrm{Fe}(\mathrm{CN})_{6}$ was chosen for consequent research work. The CL reaction was also performed in an alkaline medium in which the alkalinity was adjusted by varying the concentration of $\mathrm{NaOH}$ in the $\mathrm{K}_{3} \mathrm{Fe}(\mathrm{CN})_{6}$ solution. The effect of the $\mathrm{NaOH}$ concentration on the $\mathrm{CL}$ intensity was examined. The CL intensity increased, and reached the maximum value at $1.0 \mathrm{M} \mathrm{NaOH}$. Therefore, $1.0 \mathrm{M} \mathrm{NaOH}$ was chosen for subsequent research. A lower concentration of Rh6G decreased the CL emission, and a higher concentration produced selfabsorption of the emitted radiation. The $8.0 \mu \mathrm{M}$ Rh6G solution provided the maximum CL intensity, and was adopted for further use. The CL intensity increased with an increasing AgNPs concentration of up to $8.0 \mu \mathrm{M}$, and then began to decrease when it was higher than $8.0 \mu \mathrm{M}$. Therefore, an $8.0 \mu \mathrm{M}$ AgNPs concentration was chosen for further experiments. The effect of a negative high voltage of PMT and the flow rate on the $C L$ reaction was also examined. The function of negative high voltage is used to enlarge the weak CL signal, which is helpful to detect the signal. Finally, an $800 \mathrm{~V}$ negative high voltage and a $3.5 \mathrm{~mL} / \mathrm{min}$ flow rate were recommended to achieve the greatest precision, instrument wastage cost-effective mess, minimum reagent consumption, and low waste released.

\section{Analytical performance}

Under the optimized conditions, $\Delta \mathrm{CL}$, the difference of the $\mathrm{CL}$ intensity in the absence and presence of nitrazepam, had a 

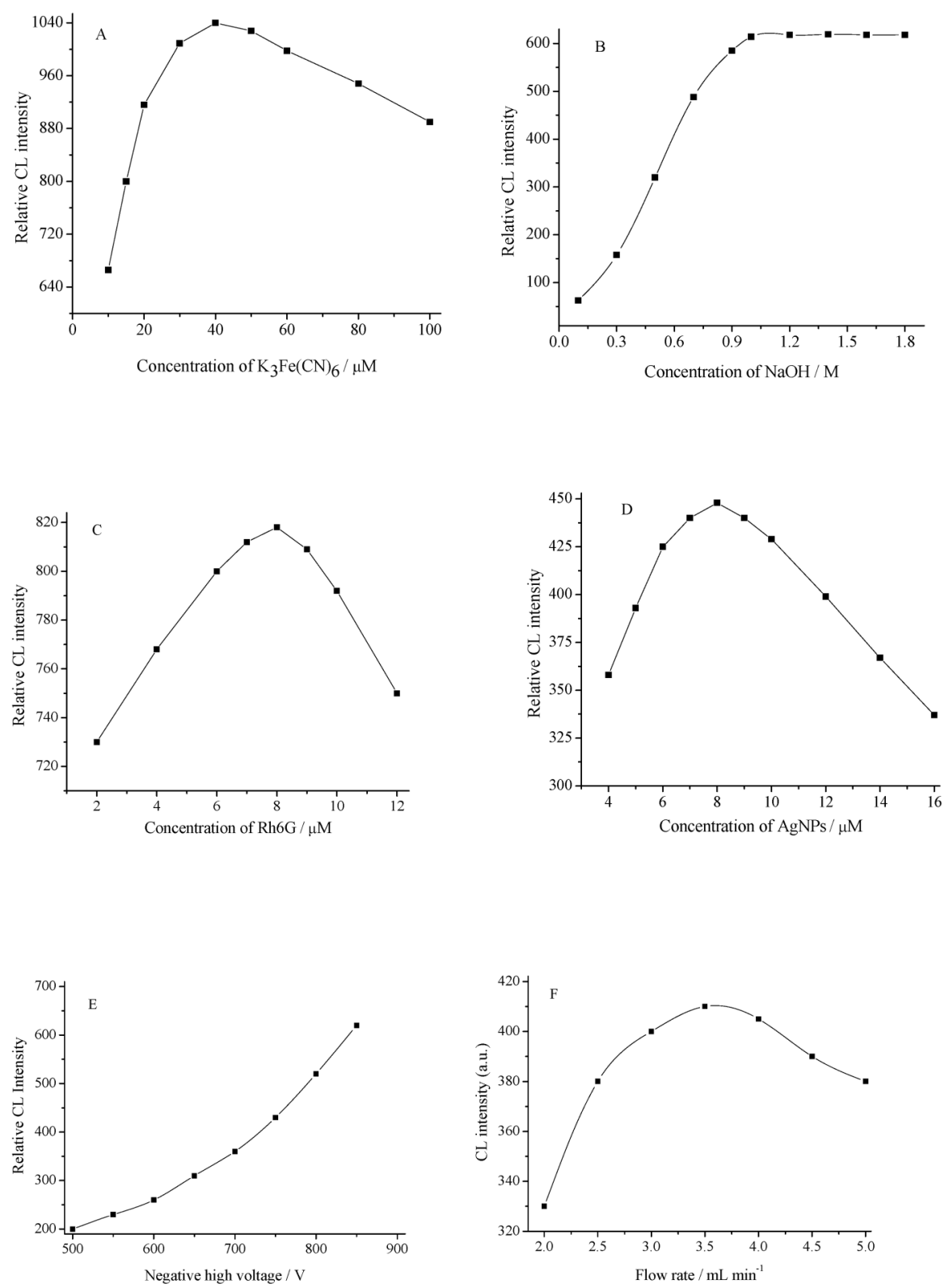

Fig. 3 Effects of the reaction conditions on the $\mathrm{CL}$ intensity. (A) $\mathrm{K}_{3} \mathrm{Fe}(\mathrm{CN})_{6}$ concentration, (B) $\mathrm{NaOH}$ concentration, (C) Rh6G concentration, (D) AgNPs concentration, (E) negative high voltage, (F) flow rate. Conditions: $40.0 \mu \mathrm{M} \mathrm{K} \mathrm{K}_{3} \mathrm{Fe}(\mathrm{CN})_{6} ; 1.0 \mathrm{M} \mathrm{NaOH} ; 8.0 \mu \mathrm{M}$ Rh6G; $8.0 \mu \mathrm{M}$ AgNPs; $0.1 \mu \mathrm{M}$ nitrazepam.

linear relationship with the nitrazepam concentration, ranging from $1.0 \mathrm{nM}-10.0 \mu \mathrm{M}$ (Fig. 4). The linear-regression equation was expressed as $\Delta \mathrm{CL}=2217.7 c+221.3(c=10 \mu \mathrm{M}, \quad r=$ 0.9998). The relative standard deviation (RSD) for the determination of $10.0 \mu \mathrm{M}$ nitrazepam was $2.1 \%(n=11)$. The detection limit $(3 \sigma)$ of the method was estimated to be $0.1 \mathrm{nM}$. The injection throughputs were $120 \mathrm{~h}^{-1}$. A comparison of the analytical performance of recently published methods with the proposed method for the determination of nitrazepam is summarized in Table 1.

\section{Interference study}

The influence of some common inorganic ion and related organic compounds was studied by the determination of a $0.1 \mu \mathrm{M}$ nitrazepam solution. The tolerance limit was taken as the amount that caused a relative error of $\pm 5 \%$ in the peak height. The results showed that no interference had been found when including up to 500-fold glucose, sucrose, starch, dextrin, lactose, cysteine and glutathione; 300 -fold $\mathrm{Fe}^{3+}, \mathrm{Fe}^{2+}, \mathrm{Zn}^{2+}, \mathrm{Ca}^{2+}$, $\mathrm{Ba}^{2+}, \mathrm{Ag}^{+}, \mathrm{Cl}^{-}, \mathrm{SO}_{4}{ }^{2-}, \mathrm{NO}_{3}{ }^{-}, \mathrm{NO}_{2}{ }^{-}, \mathrm{PO}_{4}{ }^{3-}$, urea and methanol; 100-fold carboxymethyl cellulose, ascorbic acid and 50-fold phenylalanine, creatine.

\section{Applicability of the proposed method}

The method was applied to determine nitrazepam in CocaCola beverage. Coca-Cola beverage was purchased from the local market, and was analyzed without any pretreatment. First, $10.0 \mathrm{~mL}$ of Coca-Cola beverage was pipetted into a $100.0-\mathrm{mL}$ volumetric flask and diluted with water for the determination of nitrazepam. The results are given in Table 2.

The method was also applied to determine nitrazepam in spiked human urine and plasma. Samples of urine and plasma 


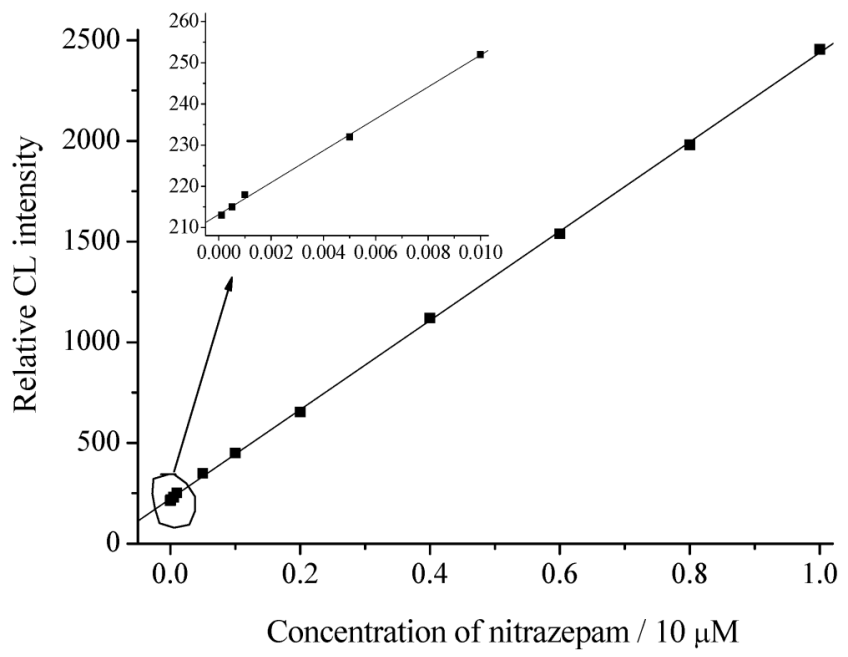

Fig. 4 Calibration curve for the determination of nitrazepam in the range of $1.0-0.1 \mu \mathrm{M}$ (inset) and $0.5-10.0 \mu \mathrm{M}$. Conditions: $40.0 \mu \mathrm{M}$ $\mathrm{K}_{3} \mathrm{Fe}(\mathrm{CN})_{6} ; 1.0 \mathrm{M} \mathrm{NaOH} ; 8.0 \mu \mathrm{M}$ Rh6G; $8.0 \mu \mathrm{M}$ AgNPs.

Table 1 Comparison of the analytical performance of our method with other reported methods

\begin{tabular}{|c|c|c|c|c|}
\hline Method & $\begin{array}{c}\text { Linear range/ } \\
\mu \mathrm{g} \mathrm{mL}^{-1}\end{array}$ & $\begin{array}{c}\text { Detection } \\
\text { limit/ } \\
\mu \mathrm{g} \mathrm{mL} \mathrm{mL}^{-1}\end{array}$ & $\begin{array}{l}\text { Applica- } \\
\text { tion }\end{array}$ & Ref. \\
\hline \multirow[t]{2}{*}{ Spectrophotometry } & $0-40$ & 0.1181 & Tablets & 3 \\
\hline & $1-24$ & 0698 & Tablets & 4 \\
\hline Fluorimetry & $10-150$ & 5 & Tablets & 5 \\
\hline \multirow[t]{2}{*}{ Voltammetry } & $28-140$ & 1.3 & Tablets & 6 \\
\hline & $14.1-168.8$ & 1.8 & Beverages & 7 \\
\hline \multirow[t]{2}{*}{ LC-MS/MS } & $0.001-0.2$ & $1.25 \times 10^{-4}$ & Urine & 8 \\
\hline & $2.5 \times 10^{-4}-5 \times 10^{-3}$ & $1.0 \times 10^{-4}$ & Oral fluid & 9 \\
\hline CZE-DAD & $17.0-90.9$ & 3.4 & Beverage & 10 \\
\hline CE-UV & $0.2-16.7$ & 0.2 & - & 11 \\
\hline AgNPs-CL & $2.8 \times 10^{-4}-2.8$ & $2.8 \times 10^{-5}$ & $\begin{array}{l}\text { Beverage, } \\
\text { urine, } \\
\text { plasma }\end{array}$ & $\begin{array}{l}\text { This } \\
\text { work }\end{array}$ \\
\hline
\end{tabular}

Table 2 Determination nitrazepam in Coca-Cola beverage, urine and plasma $(n=5)$

\begin{tabular}{lcrrrr}
\hline \multirow{2}{*}{ Sample } & $\begin{array}{c}\text { Concentration/ } \\
\mu \mathrm{M}\end{array}$ & $\begin{array}{c}\text { Added/ } \\
\mu \mathrm{M}\end{array}$ & $\begin{array}{c}\text { Founded/ } \\
\mu \mathrm{M}\end{array}$ & $\begin{array}{c}\text { Recovery, } \\
\%\end{array}$ & $\begin{array}{c}\text { RSD, } \\
\%\end{array}$ \\
\hline Coca-Cola & \multirow{2}{*}{ Not found } & 4.0 & 4.10 & 102.5 & 1.10 \\
beverage & & 6.0 & 5.84 & 97.3 & 2.04 \\
& & 8.0 & 7.92 & 99.0 & 2.05 \\
Urine & \multirow{2}{*}{1.0} & 1.0 & 2.01 & 101.0 & 1.61 \\
& & 1.2 & 2.19 & 99.2 & 2.03 \\
Plasma & \multirow{2}{*}{1.0} & 1.0 & 1.98 & 98.9 & 2.30 \\
& & 1.2 & 2.19 & 99.5 & 2.20 \\
\hline
\end{tabular}

were collected from healthy persons. An aliquot of a standard nitrazepam solution was added to $1.0 \mathrm{~mL}$ of urine or plasma in a centrifuge tube and mixed for $2 \mathrm{~min}$. Then, $2.0 \mathrm{~mL}$ of acetonitrile was added for deproteination. This mixture was then centrifuged for $15 \mathrm{~min}$ at $5000 \mathrm{rpm}$. The protein-free supernatant was transferred into another centrifuge tube and dried with an $\mathrm{N}_{2}$ stream. The residue was dissolved and diluted to $5.0 \mathrm{~mL}$ with water for the determination of nitrazepam. The

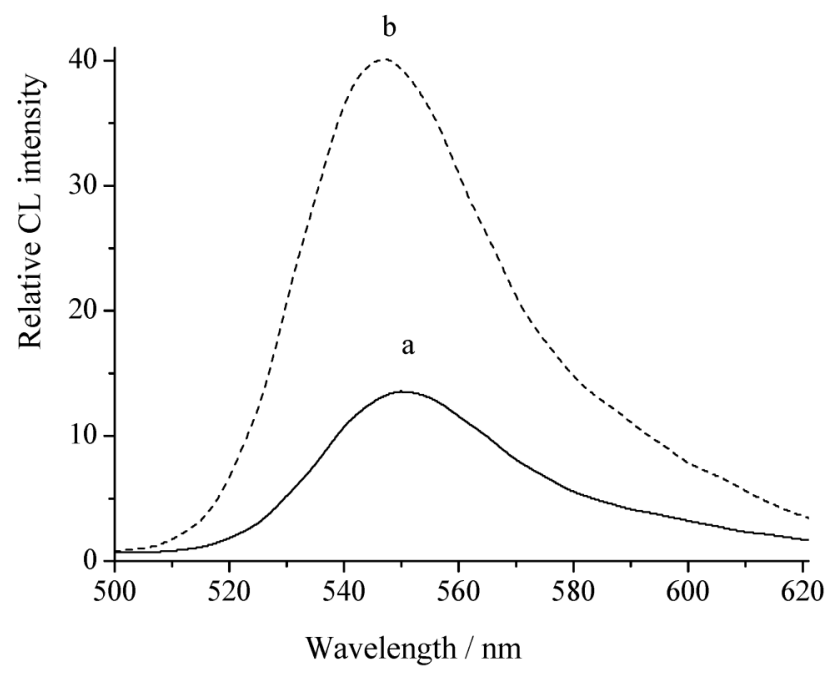

Fig. $5 \mathrm{CL}$ spectra for the $\mathrm{K}_{3} \mathrm{Fe}(\mathrm{CN})_{6}-\mathrm{Rh} 6 \mathrm{G}-\mathrm{AgNPs} \mathrm{CL}$ system in the absence (a) and presence (b) of nitrazepam. Conditions: $40.0 \mu \mathrm{M}$ $\mathrm{K}_{3} \mathrm{Fe}(\mathrm{CN})_{6} ; 1.0 \mathrm{M} \mathrm{NaOH} ; 8.0 \mu \mathrm{M}$ Rh6G; $8.0 \mu \mathrm{M}$ AgNPs; $1.0 \mu \mathrm{M}$ nitrazepam.

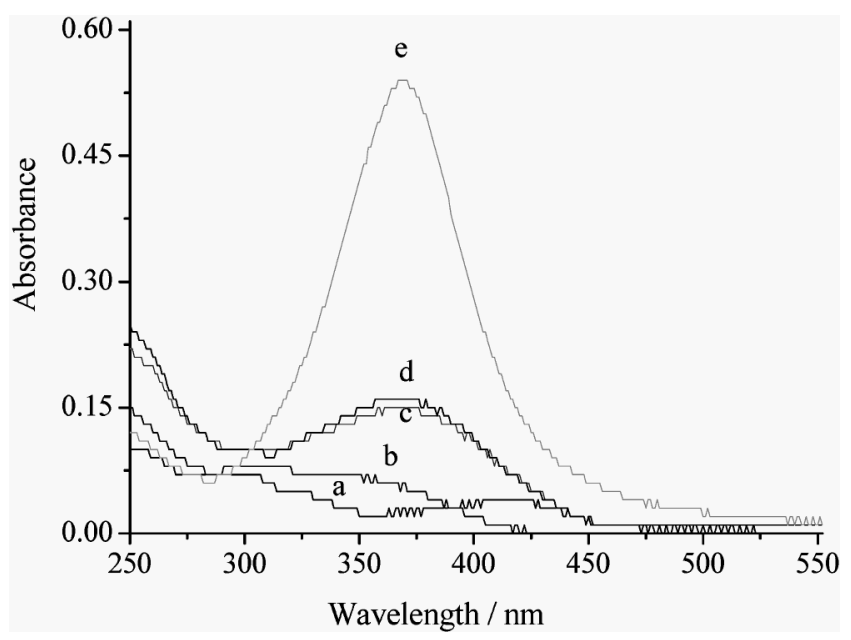

Fig. 6 UV-vis absorption spectra. a. $\mathrm{K}_{3} \mathrm{Fe}(\mathrm{CN})_{6}$, b. nitrazepam, c. $\mathrm{K}_{3} \mathrm{Fe}(\mathrm{CN})_{6}$-nitrazepam, d. $\mathrm{K}_{3} \mathrm{Fe}(\mathrm{CN})_{6}$-nitrazepam-Rh6G, e. $\mathrm{K}_{3} \mathrm{Fe}(\mathrm{CN})_{6}$-Rh6G-nitrazepam-AgNPs. $\quad$ Conditions: $\quad 40.0 \mu \mathrm{M}$ $\mathrm{K}_{3} \mathrm{Fe}(\mathrm{CN})_{6} ; 1.0 \mathrm{M} \mathrm{NaOH} ; 8.0 \mu \mathrm{M}$ Rh6G; $8.0 \mu \mathrm{M}$ AgNPs; $1.0 \mu \mathrm{M}$ nitrazepam.

RSD and recovery were tested by using the standard-addition method. The results are listed in Table 2.

\section{Possible CL mechanism}

In order to investigate the reaction mechanism of $\mathrm{CL}$ enhancement, and to confirm the emission species, the CL spectra of the $\mathrm{K}_{3} \mathrm{Fe}(\mathrm{CN})_{6}$-Rh6G-AgNPs system in both the absence and presence of nitrazepam were measured. The results (Fig. 5) showed that their CL spectra exhibited the same emission peak at $550 \mathrm{~nm}$, which was in agreement with that of the fluorescent spectrum of Rh6G. This indicated that in both cases the CL emission was from the excited state of Rh6G.

A closer examination of the UV-vis spectra of the CL system can provide insight for understanding a possible CL mechanism. The UV-vis absorption spectra of various CL system components were recorded. As shown in Fig. $6, \mathrm{~K}_{3} \mathrm{Fe}(\mathrm{CN})_{6}$ had two weak 


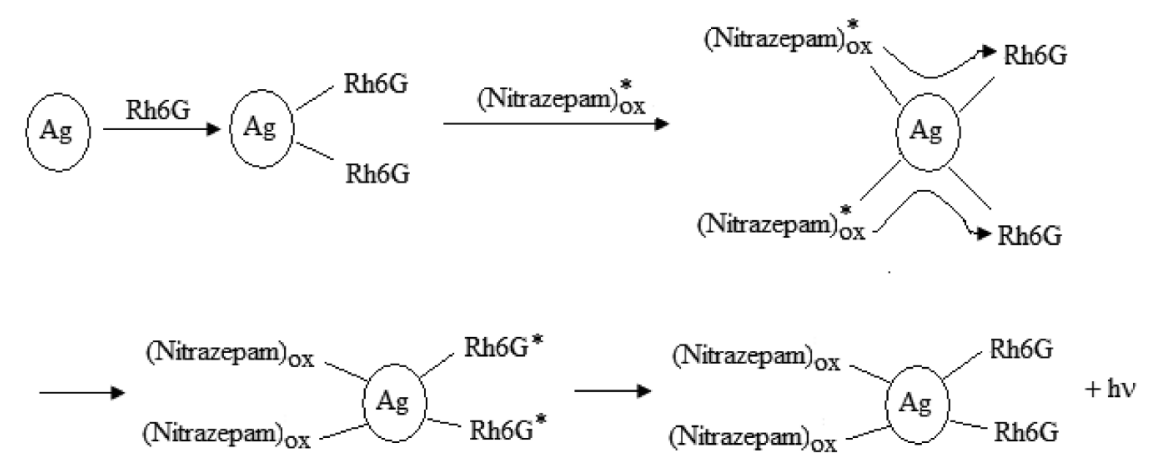

Scheme 1

absorptions at 300 and $420 \mathrm{~nm}$ (curve a) and nitrazepam had an absorption peak at $340 \mathrm{~nm}$ (curve b); however, the mixed $\mathrm{K}_{3} \mathrm{Fe}(\mathrm{CN})_{6}$ with nitrazepam had a absorption peak at around $370 \mathrm{~nm}$ (curve c), which meant that an obvious reaction occurred between $\mathrm{K}_{3} \mathrm{Fe}(\mathrm{CN})_{6}$ and nitrazepam. The absorption peak of the $\mathrm{K}_{3} \mathrm{Fe}(\mathrm{CN})_{6}$-nitrazepam-Rh6G system was also at $370 \mathrm{~nm}$, and the absorption intensity was slightly enhanced (curve d). At the same time, the absorption peak of Rh6G at $525 \mathrm{~nm}$ almost disappeared. After mixing AgNPs with $\mathrm{K}_{3} \mathrm{Fe}(\mathrm{CN})_{6}$-nitrazepamRh6G (curve e), the absorption peak of AgNPs at $394 \mathrm{~nm}$ disappeared, and the absorption peaks of the $\mathrm{K}_{3} \mathrm{Fe}(\mathrm{CN})_{6^{-}}$ nitrazepam-Rh6G system at $370 \mathrm{~nm}$ was remarkably enhanced. From these investigations, it was concluded that the $\mathrm{K}_{3} \mathrm{Fe}(\mathrm{CN})_{6}$ nitrazepam-Rh6G reaction would take place, and this reaction was significantly enhanced after AgNPs was injected into the system, which indicated that the unique properties of AgNPs should be responsible for the sensitized CL assay.

It was reported that $-\mathrm{NH}_{2}$ can be adsorbed onto AgNPs. ${ }^{21}$ The effect of the AgNPs on the $\mathrm{K}_{3} \mathrm{Fe}(\mathrm{CN})_{6}$-nitrazepam-Rh6G system was deduced as follows: $\mathrm{K}_{3} \mathrm{Fe}(\mathrm{CN})_{6}$ could oxidate nitrazepam and produce energy easily by catalyzing of AgNPs, which induced the transition of oxidized nitrazepam* from its ground state to the excited state. The oxidized nitrazepam* and Rh6G could be absorbed to the surface of AgNPs, and the distance between them was much shortened. ${ }^{18,22}$ In this way, it was easy for the energy to be transferred from oxidized nitrazepam* to the ground state of Rh6G. Therefore, it was an advantage for the ground state of Rh6G to gain more energy from oxidized nitrazepam* and to produce more Rh6G*. The more Rh6G* that returned to the ground state, the more was CL increased. In other words, with the aid of AgNPs, Rh6G was well excited and the CL intensity was greatly enhanced.

On the basis of the above discussion, the possible mechanism was expressed simply, as Scheme 1:

$$
\mathrm{K}_{3} \mathrm{Fe}(\mathrm{CN})_{6}+\text { nitrazepam } \longrightarrow \mathrm{K}_{4} \mathrm{Fe}(\mathrm{CN})_{6}+\left[(\text { nitrazepam })_{\mathrm{ox}}\right]^{*}
$$

\section{Conclusions}

A novel CL method has been established for the determination of nitrazepam, based on the enhancement by AgNPs of the CL of $\mathrm{K}_{3} \mathrm{Fe}(\mathrm{CN})_{6}$ - $\mathrm{Rh} 6 \mathrm{G}$ reaction. It offers the advantages of simplicity, rapidity, high sensitivity and wide linear range, and has a potential application in complex samples. This work is of great significance for investigating other CL reactions sensitized by new and efficient catalysts. If combined with separation techniques, the approach may be extended to complicated environmental and food samples.

\section{Acknowledgements}

This work was supported by the Natural Science Foundation of Shanxi (No. 2013011013-3), and all of the authors express their deep thanks.

\section{References}

1. H. Ashton, Drugs, 1994, 48, 25.

2. H. D. Revanasiddappa, S. M. Mallegowda, H. N. Deepakumari, and K. B. Vinay, Asian J. Biochem. Pharm. Res., 2011, 1, 70.

3. R. Sinan and M. Q. Al-Abachi, J. Univ. Anbar Pure Sci., 2009, 3, 6 .

4. J. Dolejšová, P. Solich, C. K. Polydorou, M. A. Koupparis, and C. E. Efstathiou, J. Pharm. Biomed. Anal., 1999, 20, 357.

5. R. Jain, R. Mishra, and A. Dwivedi, J. Sci. Ind. Res., 2009, 68, 540.

6. N. D. McGuire, K. C. Honeychurch, and J. P. Hart, Electroanalysis, 2009, 21, 2165.

7. H. H. Lee, J. F. Lee, S. Y. Lin, Y. Y. Lin, C. F. Wu, M. T. Wu, and B. H. Chen, Clin. Chim. Acta, 2013, 420, 134.

8. M. Jang, H. Chang, W. Yang, H. Choi, E. Kim, B. Yu, Y. Oh, and H. Chung, J. Pharm. Biomed. Anal., 2013, 74, 213.

9. W. Rebecca, D. Philip, and D. Michael, Electrophoresis, 2007, 28, 3553.

10. Y. Suzuki, H. Arakawa, and M. Maeda, Biomed. Chromatogr., 2004, 18, 150.

11. H. Chen, L. Lin, H. Li, and J. Lin, Coord. Chem. Rev., 2014, 263 - 264, 86.

12. Z. F. Zhang, H. Cui, C. Z. Lai, and M. J. Shi, Anal. Chem., 2005, 77, 3324.

13. S. Li, X. Zhang, Z. Yao, R. Yu, F. Huang, and X. Wei, J. Phys. Chem. C, 2009, 113, 15586.

14. J. Z. Guo, H. Cui, W. Zhou, and W. Wang, J. Photochem. Photobiol., A, 2008, 193, 89.

15. S. Li, H. Sun, D. Wang, J. Hong, S. Tao, H. Yu, X. Wang, and X. Wei, Luminescence, 2012, 27, 211.

16. X. Chen, C. Wang, X. Tan, and J. Wang, Anal. Chim. Acta, 2011, 689, 92.

17. B. Haghighi and S. Bozorgzadeh, Microchem. J., 2010, 95, 192.

18. X. Yu, Z. Jiang, Q. Wang, and Y. Guo, Microchim. Acta, 
2010, 171,17

19. L. Wang and Y. Tang, Luminescence, 2011, 26, 703.

20. N. Li, J. Gu, and H. Cui, J. Photochem. Photobiol., A, 22. X. Yu and J. Bao, J. Lumin., 2009, $129,973$. 2010, $215,185$.
21. J. S. Suh and M. Moskovits, J. Am. Chem. Soc., 1986, 108, 4711. 